\title{
Araucaria angustifolia: ácido indol butírico e diferentes clones no enraizamento de estacas
}

\author{
Renata de Almeida Maggioni $\circledast^{1 *}$ Jéssica De Cássia Tomasi ${ }^{1}$ Katia Christina Zuffellato-Ribas ${ }^{1}$ Ivar \\ Wendling ${ }^{2}$
}

${ }^{1}$ Universidade Federal do Paraná, Rua dos Funcionários, 1540 - Juvevê, CEP 80035-050, Curitiba, PR, Brasil

${ }^{2}$ Embrapa Florestas, Estrada da Ribeira, Km 111 - Parque Monte Castelo, CEP 83411-000 Colombo, PR, Brasil

\section{Original Article \\ *Corresponding author: \\ re_maggioni@ hotmail.com \\ Palavras-chave: \\ Pinheiro brasileiro \\ Espécie nativa \\ Regulador vegetal \\ Propagação vegetativa \\ Keywords: \\ Brazilian pine \\ Native species \\ Plant regulator \\ Vegetative propagation \\ Received in \\ 2018/10/18 \\ Accepted on \\ 2019/11/12 \\ Published in \\ 2020/04/03

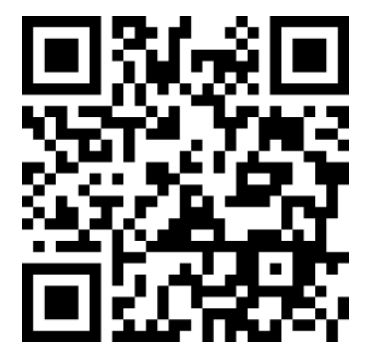

DOI:http://dx.doi.org/10.340 62/afs.v7i1.7429
RESUMO: Araucaria angustifolia, também conhecida como pinheiro brasileiro ou araucária, é uma conífera nativa do Brasil de grande importância para a Região Sul do país. Considerando sua dificuldade de propagação vegetativa, este trabalho objetivou avaliar o efeito de diferentes concentrações de ácido indol butírico (IBA) e a utilização de diferentes clones na estaquia caulinar de araucária. Brotações epicórmicas de A. angustifolia foram coletadas de cinco diferentes clones (AG9, AG14, AG16, AG24 e AG25), a partir das quais foram confeccionadas estacas caulinares $10 \pm 1 \mathrm{~cm}$ de comprimento, com corte em bisel na base e reto no ápice, mantendo $2 / 3$ de acículas na porção apical. As bases das estacas foram imersas em soluções hidroalcoólicas de 0; 8000 e $12000 \mathrm{mg} \mathrm{L}^{-1}$ de IBA, plantadas em caixas de polipropileno com vermiculita e mantidas em casa de vegetação climatizada durante 120 dias. Não houve influência do regulador vegetal IBA para nenhuma das variáveis de enraizamento. Os clones que apresentaram maiores porcentagens de enraizamento foram AG16 (38,33\%), AG24 (35\%) e AG25 (35\%). O enraizamento de estacas de araucária a partir de brotações epicórmicas pode ser considerado baixo, existindo variação significativa entre clones quanto ao potencial de enraizamento.

\section{Araucaria angustifolia: indole butyric acid and different clones in rooting cuttings}

ABSTRACT: Araucaria angustifolia, also known as Brazilian or araucaria pine, is a conifer native to Brazil of great importance to the Southern Region of the country. Considering the difficulty of the vegetative propagation of araucaria, this work aimed to evaluate the effect of different concentrations of indole butyric acid (IBA) and the use of different clones in araucaria rooting cuttings. Epicormic shoots of araucaria were collected from five different trees (AG9, AG14, AG16, AG24 and AG25), from which were made stem cuttings with $10 \mathrm{~cm} \pm 1 \mathrm{~cm}$ in length, with bevel cut at the base and rectum at the apex, maintaining $2 / 3$ of needles in the apical portion. The bases of the cuttings were immersed in hydroalcoholic solutions of $0 ; 8000$ and $12000 \mathrm{mg} \mathrm{L}^{-1}$ IBA, planted in polypropylene boxes with vermiculite and kept in a acclimatized greenhouse for 120 days. There was no influence of IBA plant regulator on any of the rooting variables. The clones that presented the highest percentages of rooting were AG16 (38.3\%), AG24 (35\%) and AG25 (35\%). The rooting of araucaria cuttings from epicoric shoots can be considered low, and there is a significant variation among clones regarding rooting potential. 


\section{Introdução}

Araucaria angustifolia (Bertol.) Kuntze, Araucareaceae, também conhecida como pinheiro brasileiro ou araucária, é uma conífera nativa do Brasil de grande importância econômica e biológica na Região Sul do país, responsável por sustentar a economia dessa região durante muitos anos (Wendling 2010).

A espécie é endêmica da Floresta Ombrófila Mista (FOM), mais conhecida como Floresta com Araucária, presente principalmente nos estados do Sul. A intensa exploração da madeira da espécie para comercialização levou a fragmentação dessa formação florestal, o que reduziu drasticamente a área ocupada por este bioma (Koch e Corrêa 2002). Atualmente, a legislação impede a exploração extrativista de A. angustifolia pelo corte para fornecimento da madeira de áreas nativas da espécie (IBAMA 2018).

Normalmente, a araucária é propagada sexuadamente. No entanto, a dificuldade no armazenamento de sementes viáveis, devido sua característica recalcitrante, aliada à produção de mudas diferentes da planta-mãe constituem inconvenientes para a reprodução sexual (MoreiraSouza e Cardoso 2003).

A propagação vegetativa em espécies florestais apresenta vantagens por garantir a formação de plantios clonais de alta produtividade e uniformidade. Porém, dificuldades associadas ao desenvolvimento de um modelo eficaz de propagação vegetativa em araucária, que garanta a produção em escala comercial, ainda existem. O resgate e rejuvenescimento de material adulto, hábito plagiotrópico e a baixa capacidade de enraizamento das brotações são grandes desafios a serem superados no processo de clonagem de indivíduos selecionados da espécie (Wendling et al. 2009).

O processo de formação radicial envolve diversos fatores como condições fisiológicas das plantas matrizes, juvenilidade dos propágulos, balanço hormonal, época de coleta, além da aplicação de reguladores vegetais (Zhang et al. 2016). Sabe-se que o material vegetal que contém características juvenis possui maior capacidade de enraizamento que materiais adultos, por apresentar condições fisiológicas, como o balanço hormonal, que favorecem o enraizamento (Hartmann et al. 2011; Stuepp et al. 2018).

Ainda, a aplicação de substâncias promotoras do enraizamento visa aumentar a porcentagem de enraizamento em menor espaço de tempo, com maior número, vigor e uniformidade das raízes, sendo o ácido indol butírico (IBA) o regulador vegetal mais empregado no enraizamento adventício (Dias et al., 2012; Pires et al. 2013). No entanto, a concentração ideal de aplicação deste regulador vegetal varia de acordo com o nível endógeno de ácido indol acético (IAA), hormônio responsável pela formação de raízes, em cada espécie ou genótipo (Hartmann et al. 2011)

Desta forma, objetivou-se avaliar o efeito de diferentes concentrações de ácido indol butírico (IBA), no enraizamento de clones selecionados de araucária, a partir de material revigorado por poda.

\section{Material e Métodos}

Brotações epicórmicas de A. angustifolia foram coletadas em setembro de 2017 , de cepas, de aproximadamente $30 \mathrm{~cm}$ de altura, de cinco diferentes árvores (AG9, AG14, AG16, AG24 e AG25), de um plantio comercial desbastado localizado no município de Campo Belo do Sul (SC). Após a coleta, o material vegetal foi transportado em isopor com água para o Laboratório de Propagação de Espécies Florestais da Embrapa Florestas, localizada em Colombo (PR), onde o experimento foi conduzido.

A partir dos propágulos coletados, foram confeccionadas estacas caulinares com $10 \mathrm{~cm} \pm 1 \mathrm{~cm}$ de comprimento, com corte em bisel na base e reto no ápice, mantendo $2 / 3$ de acículas na porção apical (Figura 1A). Após a confecção das estacas foi realizada desinfestação do material vegetal em hipoclorito de sódio a $2 \%$ por 5 minutos, seguido de lavagem em água corrente e posterior imersão em fungicida sistêmico à base de Carbendazim $2 \mathrm{~g} \mathrm{~L}^{-1}$, por 15 minutos.

Em seguida, as bases das estacas foram imersas no regulador vegetal ácido indol butírico (IBA), em solução hidroalcoólica $50 \%$, por 10 segundos, conforme os tratamentos: $0 \mathrm{mg} \mathrm{L}^{-1}, 8000$ $\mathrm{mg} \mathrm{L}^{-1}$ e $12000 \mathrm{mg} \mathrm{L}^{-1}$.

O plantio foi realizado em caixas de polipropileno de 16 litros, preenchidos com vermiculita de granulometria média e mantidas em casa de vegetação climatizada com nebulização intermitente (Figura 1B) (temperatura de $24^{\circ} \mathrm{C} \pm$ $2^{\circ} \mathrm{C}$ e umidade relativa do ar acima de $80 \%$ ), durante 120 dias.

$\mathrm{O}$ experimento foi implantado segundo um delineamento inteiramente casualizado, em esquema fatorial (3 concentrações IBA x 5 clones), com quatro repetições e cinco estacas por unidade experimental.

As variâncias dos tratamentos foram testadas quanto à homogeneidade pelo teste de Bartlett. Os dados foram então submetidos à análise de variância (ANOVA) e as variáveis que apresentaram diferença significativa pelo teste $\mathrm{F}$ tiveram suas médias comparadas pelo teste de Tukey ao nível de 5\% de probabilidade. 

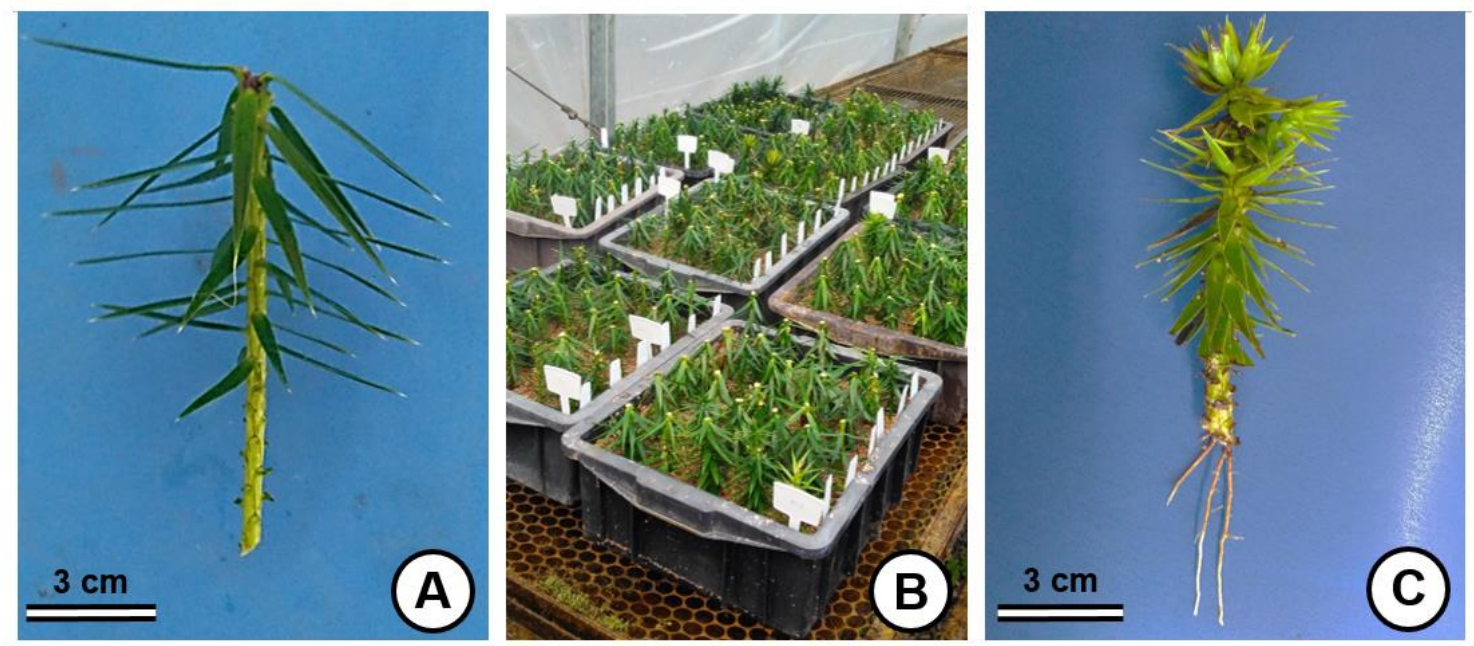

Figura 1. Estaquia de Araucaria angustifolia: estaca confeccionada (A), experimento instalado em casa de vegetação climatizada (B), estaca enraizada (C).

Após o período de 120 dias da instalação do experimento, foram analisadas as seguintes variáveis: porcentagem de estacas enraizadas (estacas vivas que emitiram raízes de, pelo menos 1 mm de comprimento); número de raízes por estaca; comprimento das três maiores raízes por estaca (cm); porcentagem de estacas vivas (estacas sem a presença de calos e sem raízes); porcentagem de estacas mortas (estacas com tecidos necrosados); porcentagem de estacas brotadas (estacas vivas, com ou sem raízes, que apresentavam brotações de novas acículas); porcentagem de estacas que mantiveram suas acículas (estacas vivas, com ou sem raízes, que mantiveram as acículas originais no momento da avaliação).

\section{Resultados e Discussão}

Não houve interação entre os fatores clones e concentrações de IBA, bem como não foi observada diferença significativa nas diferentes concentrações de IBA para nenhuma variável relacionada ao enraizamento (Tabela 1). Os clones que apresentaram maiores porcentagens de enraizamento foram AG16, AG24 e AG25, com $38,33 \%, 35 \%$ e $35 \%$ (Tabela 2).

A importância da utilização de reguladores vegetais, principalmente auxinas, para o enraizamento adventício em araucária, está relacionada não só à indução, como também com a velocidade de formação de raízes, número, comprimento e qualidade das raízes formadas (Wendling 2015).

$\mathrm{Na}$ estaquia de araucária, as concentrações de IBA recomendadas são acima de $6000 \mathrm{mg} \mathrm{L}^{-1}$ (Wendling et al., 2017). Embora tenham sido utilizadas concentrações de IBA superiores ao recomendado na literatura, não foi observada diferença significativa nas diferentes concentrações $\left(0,8000\right.$ e $\left.12000 \mathrm{mg} \mathrm{L}^{-1}\right)$ (Tabela 1$)$.

Resultados semelhantes foram observados por Wendling e Brondani (2015), em que ao avaliarem as concentrações de $0 \mathrm{mg} \mathrm{L}^{-1}, 2000 \mathrm{mg}$ $\mathrm{L}^{-1}, 4000 \mathrm{mg} \mathrm{L}^{-1}$ e $6000 \mathrm{mg} \mathrm{L}^{-1}$ de IBA em brotações epicórmicas de araucária, verificaram níveis reduzidos de enraizamento e sem efeito das concentrações de IBA. Por outro lado, Wendling (2015) recomendou a aplicação de IBA a $6000 \mathrm{mg}$ $\mathrm{L}^{-1}$ em solução hidroalcoólica ou em talco, para obter-se melhores índices de enraizamento em estacas de araucária.

Apesar das vantagens potenciais da técnica de estaquia, os resultados de enraizamento de estacas de araucária não têm apresentado a eficiência esperada, não ultrapassando os $30 \%$ (Wendling e Brondani 2015) e 53,7\% (Wendling et al. 2016), mesmo utilizando material mais juvenil. As coníferas, como a araucária, são definidas quase sempre como espécies de difícil enraizamento, principalmente quando os propágulos têm origem de plantas adultas (Ragonezi et al 2010).

As poucas tentativas no estabelecimento de protocolos de estaquia de araucária ainda apresentaram uma série de limitações para adoção em escala comercial, principalmente no que tange métodos eficientes de resgate e rejuvenescimento do material adulto (Wendling et al. 2009), indicando um comportamento recalcitrante da espécie à propagação vegetativa, mesmo em indivíduos jovens e muito jovens (origem seminal) (Pires et al., 2013). 
Tabela 1. Resultado da análise de variância para as variáveis analisadas em estacas de Araucaria angustifolia, em diferentes clones e diferentes concentrações de IBA, Colombo-PR.

\begin{tabular}{|c|c|c|c|c|c|c|c|c|}
\hline \multirow{2}{*}{$\begin{array}{l}\text { Fatores } \\
\text { de } \\
\text { variação }\end{array}$} & \multirow{2}{*}{ GL } & \multicolumn{7}{|c|}{ Quadrado Médio } \\
\hline & & $\mathbf{E E}$ & NR & CMR & $\mathbf{E V}$ & EM & EB & EMA \\
\hline & & $\%$ & & cm & $\%$ & $\%$ & $\%$ & $\%$ \\
\hline Clones & 4 & $3210,00^{*}$ & $36,12^{*}$ & $46,52 *$ & $2343,33^{*}$ & $1343,33^{*}$ & $3423,33 *$ & $1783,33^{*}$ \\
\hline IBA & 2 & $686,67^{\mathrm{ns}}$ & $14,23^{\mathrm{ns}}$ & $5,36^{\mathrm{ns}}$ & $1680,00^{*}$ & $380,00^{\mathrm{ns}}$ & $106,67^{\text {ns }}$ & $486,67^{\text {ns }}$ \\
\hline $\begin{array}{l}\text { Clones } \\
\text { x IBA }\end{array}$ & 8 & $595,00^{\mathrm{ns}}$ & $45,61^{\text {ns }}$ & $10,97^{\mathrm{ns}}$ & $713,33^{\mathrm{ns}}$ & $238,33^{\mathrm{ns}}$ & $548,33^{\text {ns }}$ & $403,33^{\mathrm{ns}}$ \\
\hline Erro & 53 & 352,07 & 5,99 & 12,56 & 520,88 & 318,99 & 499,75 & 287,29 \\
\hline Total & 59 & & & & & & & \\
\hline $\mathrm{CV}(\%)$ & & 77,11 & 88,94 & 87,44 & 38,68 & 111,63 & 48,25 & 20,34 \\
\hline
\end{tabular}

Legenda: EE: estacas enraizadas; NR: número médio de raízes por estaca; CMR: comprimento médio das três maiores raízes por estaca; EV: estacas vivas; EM: estacas mortas; EB: estacas com brotações; EMA: estacas que

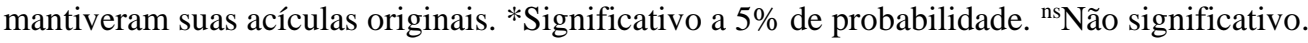

Tabela 2. Comparação de médias das variáveis de estacas de Araucaria angustifolia, em diferentes clones, Colombo-PR.

\begin{tabular}{cccccccc}
\hline \multirow{2}{*}{ CLONES } & EE & NR & CMR & EV & EM & EB & EMA \\
\cline { 2 - 8 } & $\boldsymbol{\%}$ & & $\mathbf{c m}$ & $\mathbf{\%}$ & $\boldsymbol{\%}$ & $\boldsymbol{\%}$ & $\boldsymbol{\%}$ \\
\hline AG9 & $3,33 \mathrm{~b}$ & $1,00 \mathrm{~b}$ & $1,40 \mathrm{~b}$ & $63,66 \mathrm{ab}$ & $30,00 \mathrm{a}$ & $20,00 \mathrm{~b}$ & $66,67 \mathrm{c}$ \\
AG14 & $10,00 \mathrm{~b}$ & $1,21 \mathrm{~b}$ & $3,12 \mathrm{ab}$ & $78,33 \mathrm{a}$ & $11,67 \mathrm{ab}$ & $41,67 \mathrm{ab}$ & $88,33 \mathrm{ab}$ \\
AG16 & $38,33 \mathrm{a}$ & $5,15 \mathrm{a}$ & $6,18 \mathrm{a}$ & $50,00 \mathrm{~b}$ & $11,67 \mathrm{ab}$ & $60,00 \mathrm{a}$ & $90,00 \mathrm{ab}$ \\
AG24 & $35,00 \mathrm{a}$ & $2,73 \mathrm{ab}$ & $3,49 \mathrm{ab}$ & $61,67 \mathrm{ab}$ & $3,33 \mathrm{~b}$ & $61,67 \mathrm{a}$ & $96,67 \mathrm{a}$ \\
AG25 & $35,00 \mathrm{a}$ & $3,67 \mathrm{ab}$ & $5,72 \mathrm{a}$ & $41,67 \mathrm{~b}$ & $23,33 \mathrm{ab}$ & $48,33 \mathrm{a}$ & $75,00 \mathrm{bc}$ \\
\hline Coeficiente de & 77,33 & 89,32 & 87,45 & 35,68 & 112,04 & 46,55 & 14,57 \\
Variação (\%) & & & & &
\end{tabular}

Médias seguidas de mesma letra na coluna não diferem entre si pelo teste de Tukey a 5\% de probabilidade de erro.

Estes resultados podem ser consequência de diversos fatores, atuando isoladamente ou em conjunto, como genótipo, idade, condições nutricionais da planta matriz, condições de cultivo, concentração de hormônios relacionados ao enraizamento, presença de inibidores do enraizamento, dentre outros (Wendling et al. 2009; Xavier et al. 2013), sendo necessários mais estudos que melhorem o percentual de enraizamento da espécie para recomendar o uso desta técnica para fins comerciais.

O enraizamento de estacas de araucária pode ser considerado genótipo-dependente, visto que a capacidade rizogênica das estacas foi influenciada pela origem do material genético. Wendling et al. (2017) afirmam que o desenvolvimento de protocolos específicos de propagação vegetativa de araucária por matriz selecionada é de grande importância, visto que há grande variação nos índices de enraizamento entre os indivíduos, o que também foi observado no presente trabalho.

Os clones que apresentaram maiores porcentagens de enraizamento (AG16, AG24 e AG25) foram também os que apresentaram um maior desenvolvimento do sistema radicial, variando de 3 a 5 raízes, com comprimento médio de 3,49 a $6,18 \mathrm{~cm}$ (Tabela 2). Esse desempenho revela que a potencialidade que uma estaca apresenta para formar raízes é variável com o clone, por estarem relacionadas com concentrações endógenas de substâncias importantes na indução radicial, como auxinas e cofatores do enraizamento, que variam com a origem do material genético (Fachinello et al. 2005). Por isso é importante detectar genótipos que não somente garantam características de produtividade e qualidade, mas que possuam uma alta capacidade de enraizamento para garantir a produção de mudas da espécie.

A propagação vegetativa é um excelente método utilizado para o melhoramento genético de espécies florestais, permitindo a reprodução de indivíduos geneticamente superiores e proporcionando maior uniformidade dos plantios (Pijut et al., 2011). Foi possível observar neste trabalho que a técnica de estaquia com clones estabelecidos pode representar um grande avanço na produção de mudas de A. angustifolia, por meio da propagação de indivíduos-elite. 
De acordo com Radmann et al. (2014), o número e comprimento médio das três maiores raízes por estacas são variáveis importantes para a produção de mudas, correspondendo a um melhor desenvolvimento radicial, o que contribui para a absorção mais eficiente de nutrientes e consequentemente, favorecendo a sobrevivência das mudas quando transplantadas para o campo.

Embora os índices de enraizamento tenham sido relativamente baixos, a sobrevivência das estacas e a manutenção de suas folhas originais foram, em geral, altas. Esses resultados evidenciam o adequado controle das condições ambientais (temperatura e umidade) da casa de vegetação, possibilitando alta sobrevivência do material vegetal (Zuffellato-Ribas e Rodrigues 2001). O enraizamento de estacas é influenciado por fatores endógenos e exógenos, relacionadas à planta matriz. Por mais que as condições ótimas da casa de vegetação tenham garantido a sobrevivência das estacas, os índices relativamente baixos de enraizamento podem ter sido influenciados por fatores endógenos, como concentrações insuficientes de auxinas e cofatores do enraizamento.

As maiores porcentagens de estacas com brotações foram observadas nos clones que também apresentaram maior enraizamento (Tabela 2), não tendo influência da utilização de auxina sintética. Esses resultados indicam um adequado balanço hormonal dessas estacas, onde o nível endógeno de auxina foi suficiente para promover a indução radicial, e após o enraizamento ocorreu síntese de citocinina, responsável pela formação das novas brotações (Taiz et al. 2017).

Embora os índices de enraizamento ainda não se apresentem comercialmente viáveis para a propagação vegetativa de araucária, a necessidade do desenvolvimento de protocolos específicos para cada material genético selecionado é de suma importância, principalmente no que tange a base fisiológica e bioquímica no enraizamento adventício, visto que variação na capacidade de enraizamento entre os indivíduos é notável.

\section{Conclusões}

De modo geral, o enraizamento de estacas de araucária a partir de brotações epicórmicas pode ser considerado baixo, existindo variação significativa entre clones quanto ao potencial de enraizamento.

Não houve influência da aplicação de IBA no enraizamento de estacas de $A$. angustifolia.

Há a necessidade do prosseguimento de pesquisas sobre o tema para a efetiva recomendação de um protocolo de propagação vegetativa para a espécie.

\section{Agradecimentos}

À Coordenação de Aperfeiçoamento de Pessoal de Nível Superior (CAPES), pelo apoio financeiro. À Florestal Gateados pela disponibilização do material vegetal.

\section{References}

Dias PC, Xavier A, Oliveira LS, Paiva HN, Correia ACG (2012) Propagação vegetativa de progênies de meios-irmãos de angico-vermelho (Anadenanthera macrocarpa (Benth) Brenan) por miniestaquia. Revista Árvore, 36: 389-399. doi: 10.1590/S010067622012000300001.

Fachinello JC, Hoffmann A, Nachtgal JC, Kersten E. Propagação vegetativa por estaquia. In: Fachinello JC, et al. Propagação de plantas frutíferas. Brasília: Embrapa Informações Tecnológicas, 2005. p.69-109.

IBAMA (2018) Projeto de Monitoramento do Desmatamento dos Biomas Brasileiros por Satélite. Disponível em: <http://siscom.ibama.gov.br/monitora_biomas/PM DBBS\%20-\%20MATA\%20ATLANTICA.html> Acesso em: 08 jul. 2018.

Hartmann HT, Kester DE, Davis Jr FT, Geneve RL (2011) Plant propagation: principles e practices. 8. ed. Boston: Prentice Hall, 915 p.

Koch Z, Corrêa MC (2002) Araucária: A Floresta do Brasil Meridional. Curitiba: Olhar Brasileiro, $148 \mathrm{p}$.

Moreira-Souza M, Cardoso EJBN (2003) Practical method for germination of Araucaria angustifolia (Bert.) O. Ktze. seeds. Scientia Agricola, 60(2): 389-391. doi: 10.1590/s0103-90162003000200025.

Pijut PM, Woeste KE, Michler CH (2011) Promotion of adventitious root formation of difficult-to-root hardwood tree species. Horticultural Reviews, 38: 213-251. doi: 10.1002/9780470872376.ch6.

Pires PP, Wendling I, Brondani G (2013) Ácido indolbutírico e ortotropismo na miniestaquia de Araucaria angustifolia. Revista Árvore, 37(3): 393399. doi: 10.1590/S0100-67622013000300002.

Radmann EB, Feijo AR, Goulart RC, Fischer DLO, Bianchi VJ (2014) Interação entre o genótipo e AIB no enraizamento de estacas semilenhosas de portaenxertos de pessegueiro. Nativa, 2: 129-133. doi: 10.14583/2318-7670.v02n04a08.

Stuepp CA, Wendling I, Xavier A, Zuffellato-Ribas KC (2018) Vegetative propagation and application of clonal forestry in Brazilian native tree species. 
Pesquisa agropecuária brasileira, 53 (9), 9851002. doi: 10.1590/s0100-204x2018000900002.

Taiz L, Zeiger E, Moller IA, Murphy A. (2017) Fisiologia e Desenvolvimento Vegetal. 6 ed. Porto Alegre: Artmed. 888p.

Wendling I (2010) A araucária na silvicultura brasileira. Referência: A revista da indústria da madeira, 12(108): 21-22.

Wendling I, Brondani G (2015) Vegetative rescue and cuttings propagation of Araucaria angustifolia. Revista Árvore, 39(1): 93-104. doi: 10.1590/010067622015000100009.

Wendling I (2015) Estaquia e miniestaquia de Araucaria angustifolia para produção de madeira. Colombo: Embrapa Florestas, 9p. (Comunicado técnico 350).

Wendling I, Dutra LF, Hoffmann HA, Bettio G, Hansel F (2009) Indução de brotações epicórmicas ortotrópicas para a propagação vegetativa de árvores adultas de Araucaria angustifolia. Agronomia Costarricense, 33(2): 309-319.

Wendling I, Stuepp CA, Zuffellato-Ribas KC (2016) Rooting of Araucaria angustifolia: types of cuttings and stock plants sex. Revista Árvore, 40:
1013-1021.
doi:
$10.1590 / 0100-$

67622016000600006

Wendling I, Stuepp CA, Zanette F (2017) Produção de mudas de araucária por estaquia e miniestaquia. In: Wendling I, Zanette F. Araucária: particularidades, propagação e manejo de plantios. Brasília, DF: Embrapa, 65-106p.

Xavier A, Wendling I, Silva R L (2013) Silvicultura clonal: princípios e técnicas, 2 ed. Viçosa, MG: 279 p.

Zhang W, Fan J, Tan Q, Zhao M, Cao F (2016) Mechanisms underlying the regulation of root formation in Malus hupehensis stem cuttings by using exogenous hormones. Journal Plant Growth Regulation, 35, 1-12. doi: 10.1007/s00344-0169628-8.

Zuffellato-Ribas KC, Rodrigues JD (2001) Estaquia: uma abordagem dos principais aspectos fisiológicos. Curitiba: [K. C. Zuffellato-Ribas], 39 p.

IBÁ. Indústria Brasileira de Árvores (2018). Sumário executivo 2018. Brasília: IBÁ. 6p. 